\title{
Research and Practice on the Innovation Ability Cultivation Model of Undergraduates Under the "Unity of Knowledge and Practice"
}

\author{
Xiaogang Tang ${ }^{1,}$, Sunan Wang $^{2}$, Shibing $\mathrm{Zhu}^{1}$, Litian $\mathrm{Liu}^{1}$ \\ ${ }^{1}$ School of Space Information, Space Engineering University \\ ${ }^{2}$ School of Mechanical Engineering, Xi'an Jiaotong University \\ atitantxg@163.com
}

Keywords: reform of higher education teaching, teaching concept of innovative practice, treeshaped knowledge system, laddered cultivation mode

\begin{abstract}
Under the background of the nation's innovation-driven development, college students' engineering practice and scientific and technological innovation training are the inevitable way for students to become talents, and also one of the important yardsticks for measuring the practical teaching level of higher education institutions of engineering. Based on the current situation of undergraduates' needs for innovative ability and scientific literacy, this paper proposes the "integrating of knowledge and action" innovation ability cultivation and teaching concept. By building a tree-shaped knowledge system and a laddered innovation ability cultivation model, with promotion of innovative practice methods of "undergraduate tutorial system" and "undergraduates into the lab", to effectively advance the reform of innovative practice teaching for undergraduates. The comparative results of teaching practice verified the effectiveness of the "integrating of knowledge and action" innovation ability training model and method, and on the basis of summarizing the teaching practice activities, the inspiration and suggestions for follow-up college teaching reform are proposed. The cultivation mode and method of innovation ability proposed in this paper has universal applicability, which has positive reference significance for the innovation of teaching ideas in higher education institutions and the promotion of practice teaching reform in colleges and universities.
\end{abstract}

\section{Introduction}

Driven by the $4^{\text {th }}$ industrial revolution and the economic wave represented by "artificial intelligence," "robots," and "genetic engineering," innovation-driven growth is the driving force behind growth of various economies in the world. As the main field for cultivating talents, higher education institutions are faced with remodeling of the system structure, adjustment of resource allocation and updating of teaching philosophy. In terms of teaching philosophy, higher education institutions must continuously strengthen the concept of talent-first education. China's construction of world-class universities and first-class disciplines clearly state that the implementation of comprehensive development education and the creation of innovative, compound, and comprehensive first-class talents are the fundamental mission of undergraduate education in first-class universities in China ${ }^{[1]}$.

Education in traditional universities focuses more on indirect knowledge imparting while less on direct acquisition of knowledge; more on classroom instruction while less on engineering training; more on teaching experiments while less on innovation practice. The scientific literacy and overall quality of undergraduate students need to be improved, and their ability to innovate and practice needs to be enhanced. These practical problems are not in line with the cultivation objectives for new innovative talents. Practice is not just about verifying knowledge; more importantly, it is about acquiring knowledge directly. The cultivation and practice of innovation ability in higher education institutions is an urgent need for the national development strategy and information war in the new era, which is the requirement for the development of university talents. 
China is facing economic restructuring and adjustments on the innovation-driven development strategy. How to respond to changes in talent needs, reform cultivation modes, and improve the innovative ability of undergraduates are new challenges that higher education institutions face. This paper first elaborates the practical needs of innovation ability cultivation from the three dimensions of national development strategy, demand of high-tech talents, and knowledge inheritance law, and specifically analyzes the current status of Chinese undergraduates in terms of scientific literacy, comprehensive quality, and gaps in innovation capabilities; and further this paper proposes the "integrating knowledge and action" innovation and practice teaching philosophy for undergraduates, focuses on the innovation ability cultivation knowledge system; through the establishment of a tree-shaped knowledge system and laddered innovation ability cultivation mode, through the "first classroom" and "second classroom", with promotion of "undergraduate tutorial system" and "undergraduates into the lab" and other specific innovative cultivation measures, this paper practically recommends cultivation teaching practice for innovative ability. Finally, through a comparison of teaching practice, the effectiveness of the models and methods of "integrating knowledge and action” in innovation ability cultivation of undergraduates is verified.

\section{The needs and current situation of cultivating innovative ability in higher education institutions}

To carry out innovative ability cultivation and technological innovation activities of undergraduates in higher education institutions is the requirement of the new economic wave, is a concrete reflection of the general requirements for personnel training in new technical positions, which is dictated by the knowledge acquisition and intrinsic laws of teaching.

(1) he fourth industrial revolution requires universities to cultivate talents with innovative ability and engineering practice

The $4^{\text {th }}$ industrial revolution is a brand-new technological revolution based on artificial intelligence, clean energy, robotics, quantum information technology, virtual reality, and biotechnology, and will surely promote the transformation of economic growth patterns. Under the background of the new economic wave, in order to achieve sustainable and healthy economic development in China, we must rely on innovation-driven development. We must deepen the integration of science \& technology and economy, promote the deep integration of industry, universities and research institutes, achieve seamless integration of science and technology with the industry, and continuously improve the contribution rate ${ }^{[2]}$ of the technological advancement on economic growth. The State Council's "Opinions on Vigorously Promoting Several Policies and Measures for Mass Innovation by the Public" also pointed out that entrepreneurial spirit education and entrepreneurial quality education should be incorporated into the national education system, to realize the institutionalization and systematization of entrepreneurship education and training in the whole society $^{[3]}$.

(2) Development of new high-tech requires talents with comprehensive scientific literacy and innovative practical ability

In the future, with intersected and integrated development of new high-tech, talents are required to have a comprehensive knowledge structure, higher scientific literacy (including innovation ability) and comprehensive quality. That is, technology industry practitioners in the future will have comprehensive knowledge structures such as machinery, power, control, and information, and also cognitive, practical, analytical, and innovative technological literacy, as well as logical thinking, language expression, and other comprehensive capabilities. At the same time, new scientific and technological positions require that talents have the ability of restudying, technological innovation and innovation practice. In the future, as a technology-intensive industry, in the new high-tech area, technological development is changing with each passing day, and knowledge is updated quickly. In recent years, initial results have been shown in cutting-edge technologies such as artificial intelligence, big data, and robotics have been applied in industries, transportation, securities, and 
other fields. In the future, the new high-tech industry requires practitioners to have the ability of re-learning, innovation and technology renovation, to lay a solid foundation for long-term success.

(3) Intrinsic laws of knowledge acquisition, inheritance, and education require higher education to focus on cultivation of innovative ability

In terms of knowledge acquisition, knowledge is divided into existing knowledge and new knowledge (or unknown knowledge), and existing knowledge can be taught through classroom teaching activities to enable students to quickly accept and understand, but for new knowledge, however, it needs to be acquired through a large number of learning methods such as observation, hypothesis, and tests that are actively explored (i.e., innovative practices). In the inheritance of knowledge, the process of inheritance of knowledge is also a process of continuous iteration that follows cognition, practice, analysis, and innovation.

The teaching process is a process of discarding the false and retaining the true, and constant trials and errors for students. This teaching law requires that teaching institutions must pay attention to students' innovative practice activities, provide students with trial and error opportunities and practice platforms, and enable students to recognize and acquire knowledge in repeated practice, which is the responsibility of teachers and teaching institutions.

At present, the educational objectives of higher education institutions have long lies in the level of making the educated acquire a set of knowledge and skills that are useful for specific industries and positions. They pay more attention to mastering the knowledge points and they lack effective measures to cultivate students' independence and critical thinking skills, as a result, the lack of students' innovative ability has an impact on knowledge acquisition, inheritance, and the future development of students. Through the summary of teaching and innovation practice in recent years, undergraduates in higher education institutions have the following obvious deficiencies in terms of scientific literacy, comprehensive quality and innovative practice.

(1) The scientific literacy of undergraduates in higher education institutions needs to be improved. Scientific literacy is the ability to apply scientific knowledge to identify problems and draw evidenced conclusions, including scientific knowledge, methods and judgments. Undergraduates' grasp of knowledge only stays in the classroom level and cannot find the intrinsic links between knowledge points in various subjects. For example, students cannot clearly understand the internal relations between the electrical RLC charge-discharge process and the mechanical-mass spring-damping system, and do not know that the physical system has the same representational form and essence (motion is the first attribute) after it is abstracted into a mathematical model. The undergraduates' scientific literacy needs to be improved also because the scientific methods are not formed, and there is no clear concept of the natural science methods for observation, hypothesis and test.

(2) The overall quality of undergraduates in higher education institutions needs to be enhanced. In the process of undergraduate study and practice, the overall concentration of students is mainly reflected in logical thinking, language expression, and the comprehensive application of various tools used in the face of specific problems. In recent years, teaching practice shows that undergraduates generally show a problem of conciseness (the first problem, which is caused by scientific literacy problems) and their poor ability in logical expression, poor foreign language level, poor listening and speaking ability, and lack of comprehensive computer application ability. The ability of foreign languages, computers, and logical thinking are the basic requirements and universal capabilities of undergraduate talent cultivation in internationally renowned universities.

(3) Undergraduates in higher education institutions are weak in innovative practice. At this stage, China's well-known colleges and universities pay attention to the students' "second classroom" and the cultivation of innovative models. The "second classroom" embodies the completeness of knowledge, and innovation cultivation is an important means to acquire knowledge. However, after several rounds of reforms in higher education institutions in China, the teaching methods for academic education still need to be remodeled, and insufficient grasp of advanced teaching concepts leads to the problems of undergraduates in higher education institutions such as 
"high scores but low abilities" and "great ambition but little talent". The ability of university students to practice needs to be further enhanced.

\section{3 "Integrating of knowledge and action" innovation and practice teaching philosophy}

At the Seventeenth Academician Conference of the Chinese Academy of Sciences, Chairman Xi pointed out that technology is the foundation of a country's prosperity and innovation is the soul of national progress ${ }^{[4]}$. Harvard University also applies the concept of innovative education throughout the entire teaching activity, regarding innovative practice as a basic ability for students to develop habits of self-reliance and lifelong learning so that they can develop knowledge, enhance understanding, and serve the society in their future lives ${ }^{[5]}$.

In the face of the new economic wave and the need for new scientific and technological talents, as well as the lack of scientific literacy and innovative practices of undergraduates in higher education institutions, higher education institutions urgently need to innovate the teaching philosophy and find effective new methods in practical teaching, to link up the undergraduates' knowledge system, enhance hands-on practical ability, improve learning initiative, and to finally achieve the enhancement of scientific literacy and comprehensive quality of undergraduates in higher education institutions. Through the exploration of teaching practice in recent years, the author sums up the teaching philosophy and experiences of innovative practice and gradually forms the core teaching philosophy and knowledge system of "integration between knowledge and action" innovative ability cultivation (Figure 1).

(1) It is better to teach a man fishing than to give him fish

The new economic wave and the cultivation of talents for science and technology require that practitioners not only have rich professional discipline knowledge, precise equipment control capabilities, but also have innovative thinking and innovative problem-solving abilities. This poses new demands for personnel training modes. At the same time, the new economic growth mode requires practitioners to quickly update their knowledge systems, adapt to changes, and have relearning abilities. "It is better to teach a man fishing than to give him fish," the process of cultivating undergraduates' ability to innovate in science and technology is the process of teaching undergraduate "fishing".

(2) Practice is not only about verifying knowledge, but more importantly, about directly acquiring knowledge

In China's current education system, students rarely have access to engineering practices and innovative practices before receiving higher education. In the process of receiving higher education, they also faced the problems of relatively independent professional curriculum setting and lack of multidisciplinary knowledge integration. The current trend of multi-discipline integration brought about by the development of science and technology is becoming more and more significant, which leads to many difficulties for the cultivation of undergraduates' scientific and technological innovation abilities. At the same time, a lack of complete knowledge in learning is due to the establishment of disciplines in higher education institutions and so on. " Practice is not only about verifying knowledge, but more importantly, about directly acquiring knowledge." Higher education institutions should pay more attention to innovative practice cultivation and achieving undiscovered knowledge, that is, innovation.

(3) Solidify foundation, guide exploration, shape the personality traits of pursuing excellence, and daring to challenge

The educational objectives of higher education institutions have long been on the level that allows the educated to acquire a set of knowledge and skills that are useful for specific industries and positions. They pay more attention to the grasp of knowledge points, and lack effective measures to cultivate the students' independence and critical thinking ability, as a result, students lack innovative ability ${ }^{[7]}$. Therefore, in the cultivation of innovative ability in higher education institutions, we must follow the basic concept of consolidating basic knowledge, guiding thinking and exploration, and strengthening engineering practice, and promoting the cultivation concept of 
shaping the personality traits of pursuing excellence, and daring to challenge, creating innovative teaching practice in higher education institutions, so that the innovation becomes a habit of students.

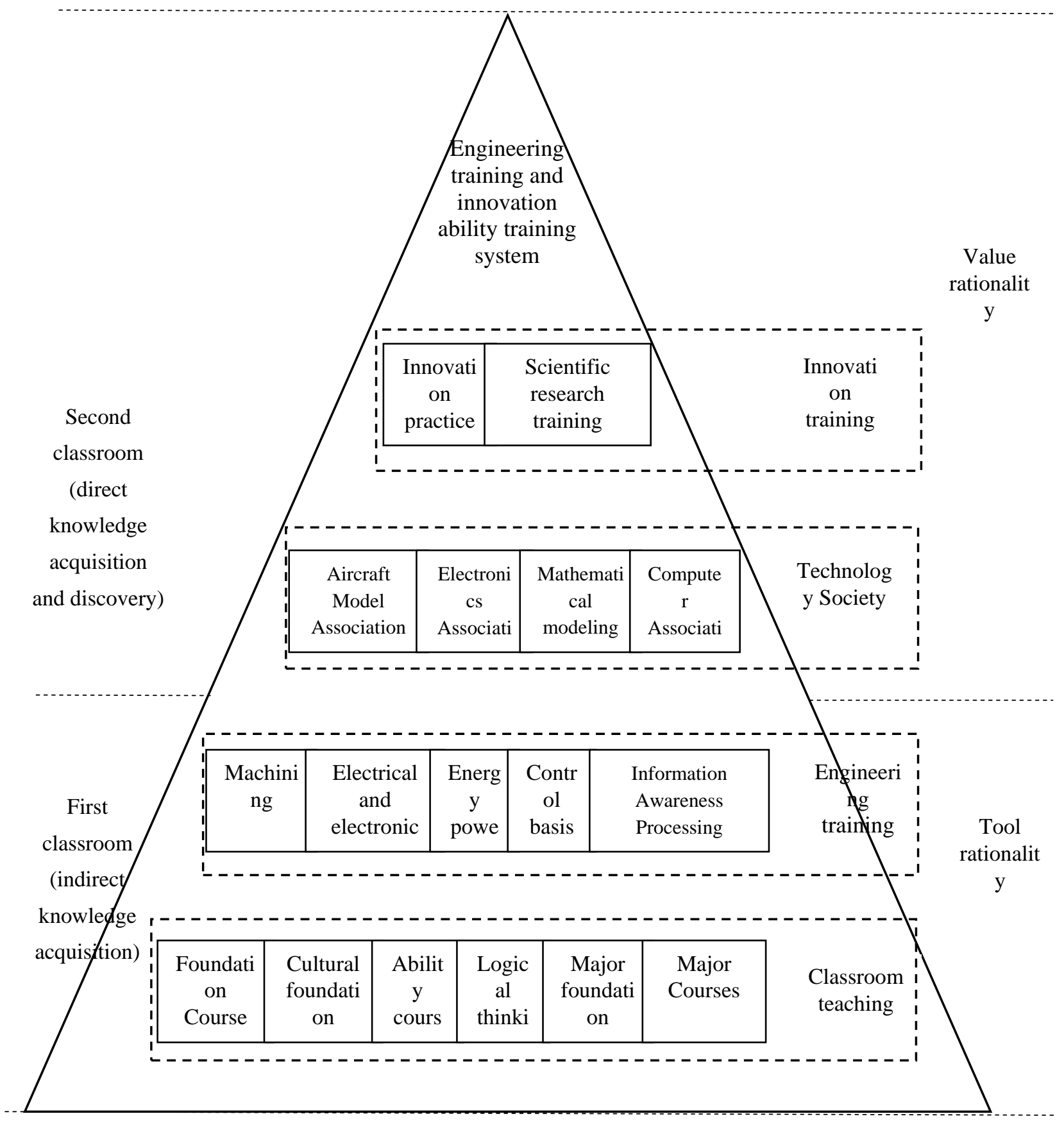

Figure 1 Undergraduate engineering training and innovation ability training system

The "knowledge and action" innovation ability cultivation knowledge system is divided into four levels: subject teaching, engineering training, science and technology societies, and innovation cultivation. Among them, subject teaching and engineering training are of the first classroom teaching activities. The purpose is to enable undergraduates to quickly and indirectly acquire existing knowledge through classroom teaching; and science and technology societies and innovation cultivation are of the second classroom teaching activities, the purpose of which is to enable undergraduates to acquire or discover new knowledge directly through practice and training. It can be known from the innovation ability training knowledge system that the first classroom is a basic teaching, which focuses on the tool rational cultivation of knowledge, while the second classroom is a practical or innovative teaching, focusing on the value cultivation of knowledge. "Integrating of knowledge and action" fosters the knowledge system into a triangular form and 
reflects the importance of the first classroom teaching. More importantly, it is known looking back at the "knowledge and action" innovation ability cultivation knowledge system that the second classroom, that is, practical or innovative teaching, has a greater proportion in the breadth of knowledge training.

\section{4 "Integrating knowledge and action"-undergraduate students' innovative ability cultivation method}

In view of the existing problems and urgent needs of practical teaching and innovation training in the current higher education institutions, the author of this paper has practiced the teaching concept of "integrating of knowledge and action" in the communication engineering major, and gradually formed a set of "integrating of knowledge and action" innovation cultivation method mode for undergraduates in higher education institutions.

\section{Undergraduate’s Science and Technology Innovation Abilities}
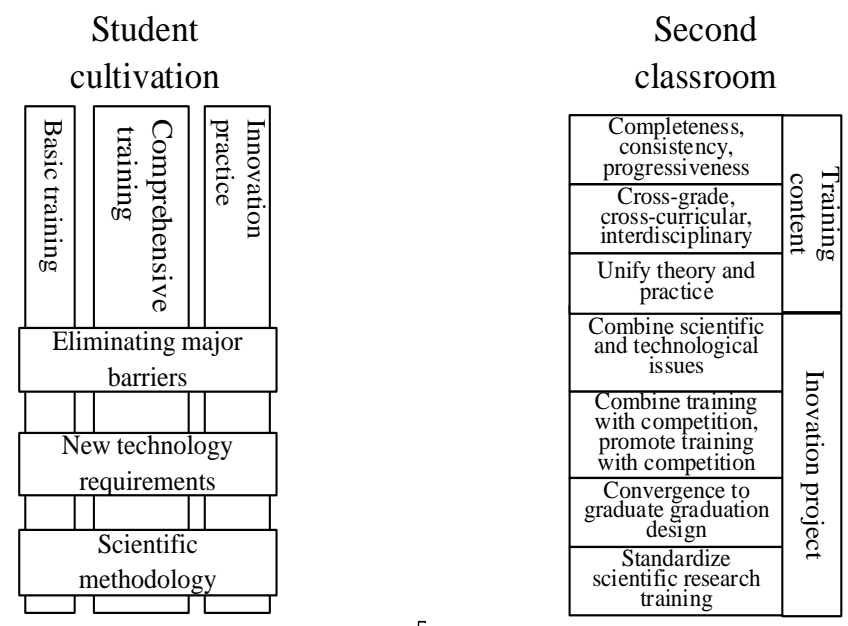

System

guarantee

\begin{tabular}{|c|}
\hline $\begin{array}{c}\text { Students' } \\
\text { innovation tutor }\end{array}$ \\
\hline $\begin{array}{c}\text { Innovation team } \\
\text { training }\end{array}$ \\
\hline $\begin{array}{c}\text { Students' } \\
\text { Innovation } \\
\text { Center }\end{array}$ \\
\hline
\end{tabular}

Figure 2 Method for cultivating innovative ability of undergraduates

\subsection{Tree- shaped knowledge system and laddered training mode are the core methods of innovation practice}

(1) Open up major barriers and establish a tree-shaped knowledge system for undergraduates

The university is training talents for tomorrow's society. If it is over-specialized, the talents cultivated will not only meet the narrow conditions but also have no potential for sustainable development ${ }^{[5]}$. Establishing a tree-shaped undergraduates' knowledge system refers to the guidance of scientific methodology and the demand for new-tech talents in the future. Establishing undergraduates' tree-shaped professional knowledge system serves as "roots" and related professional knowledge serves as trunk and branches, to eliminate major barriers and adapt to the needs of general knowledge personnel for general-purpose talents.

According to the statistics of the undergraduates of communication engineering majors in recent years (as shown in Table 1), more than $50 \%$ of undergraduates did not engage in the work related to their majors after graduation. Therefore, it is necessary to expand the basic knowledge of related positions of undergraduates so that undergraduates can understand the current high-tech development situation and quickly enter the role after appointment.

Perfecting the knowledge structure, especially the cross-disciplinary and multidisciplinary integration of knowledge structures, plays an important role in scientific and technological innovation activities. Taking the communication major as an example, to train undergraduates to establish a tree-shaped knowledge system that applies communication as root, information technology as trunk, automatic control, mechanical electronics, artificial intelligence, and virtual 
reality as branches, in order to eliminate the major barriers and perfect the knowledge structure of undergraduates.

Table 1 Statistics of positions for undergraduates graduated from the major of communications engineering

\begin{tabular}{|c|c|}
\hline Position & Proportion \\
\hline Communication & $43 \%$ \\
\hline Information & $19 \%$ \\
\hline Control & $16 \%$ \\
\hline Mechanics & $15 \%$ \\
\hline Other & $7 \%$ \\
\hline
\end{tabular}

(2) Laddered cultivation mode for innovation practice

The laddered cultivation mode refers to cultivation according to the grades of undergraduate students in three stages: basic training, comprehensive training, and innovative practice. An innovation training mode of "focus on foundation during the freshman year, entry into lab during the sophomore year, science and technology innovation during the junior year, and convergence of graduation design during the senior year" is created to ensure the continuity of innovation practice and the continuity of knowledge recognition.

The basic training phase mainly focuses on the first and second grades of universities. On the one hand, it cultivates the self-study ability of undergraduates; the comprehensive training stage focuses on the second and third grades of universities. On the one hand, it deepens the understanding of professional knowledge among undergraduates. On the other hand, it trains undergraduates the ability to apply tools to try to solve practical problems; the innovation practice stage is aimed at undergraduates in the third and fourth grades, guiding undergraduates to develop relevant subject knowledge, and guiding undergraduates to participate in scientific research projects or scientific and technological activities, cultivating students to apply innovative thinking to analyze problems, and the ability to apply innovative methods to solve problems. Finally, convergence of graduation design, it further consolidates innovation and practice issues, helps students write high-level graduation thesis, and encourages the publication of academic articles, to lay a solid foundation and logical thinking skills for the subsequent graduate education.

\subsection{Mutual complementarity between "first classroom" and "second classroom" is the source of innovation}

The future industrial revolution and economic development require practitioners to have a broad knowledge base, a broad vision, and the ability to respond to uncertain environment and random changes and innovative thinking ${ }^{[6]}$. With the objective of "integrating knowledge and action", to establish and perfect the "second classroom" of technological innovation. It runs through the idea of "practice is not only about verifying knowledge, but more importantly, about directly acquiring knowledge". The purpose is to enable undergraduates to verify knowledge and acquire new knowledge through practice based on understanding knowledge.

The "second classroom" practical teaching is a comprehensive, design-based, and research-based practical teaching based on theoretical knowledge. It is a practical teaching centered on inquiry. Through such practical teaching, it not only deepens the undergraduates' understanding of theoretical knowledge, but also cultivates undergraduates' ability to explore the unknown through practice. Taking the communications engineering major as an example, the curriculum system for the cultivation of scientific and technological innovation abilities has now been established, shown as in Figure 3. 
First classroom

\begin{tabular}{|c|c|c|c|c|c|c|c|}
\hline $\begin{array}{c}\text { Principle of } \\
\text { communication }\end{array}$ & Computer network & $\begin{array}{c}\text { Aerospace } \\
\text { Communications }\end{array}$ & \multirow{3}{*}{ Complement } & \multicolumn{4}{|c|}{ Innovative project design } \\
\hline $\begin{array}{l}\text { Microcomputer } \\
\text { principle }\end{array}$ & Embedded Systems & Language basis & & $\begin{array}{l}\text { Electromechanical } \\
\text { foundation }\end{array}$ & Con & basis & Artificial intelligence \\
\hline Mathematics & Physics & Signals and Systems & & Dialectics o & ture & \multicolumn{2}{|c|}{ Scientific methodology } \\
\hline
\end{tabular}

Figure 3 Science and technology innovation ability training courses for undergraduates

\section{3 "Undergraduate tutorial system" and "undergraduates into the lab" are effective measures for innovative practice}

In innovative teaching methods, a series of effective teaching methods such as the "undergraduate tutorial system" and "undergraduates into the lab", "going out of the school gate, attending competition in replacement of training" are well-established, to ensure to carry out the innovative practice activities well.

The tutorial system is a unique training system for undergraduates at Oxford University. Tutorial system is the reason why Oxford University is so outstanding. In the tutorial system, the teachers inevitably impart knowledge, it does not aim at imparting knowledge, yet encourages students to actively develop their autonomic learning ability, independent work ability, and skills of analysis and criticism. The core is a theory that teaches young students to think independently ${ }^{[7]}$. The implementation of the "undergraduate innovation tutorial system" is a useful supplement to the current undergraduate teaching system.

The "undergraduates into the lab" activity enables students to stay close to the scientific research environment and receive scientific research training to lay the foundation for later success. "Going out of the school gate, attending competition in replacement of training" has a positive influence on broadening students' horizons and improving students' initiative and enthusiasm for learning.

\section{Analysis and enlightenment on the practice effect of undergraduates' innovation ability cultivation}

\section{1 "Integrating knowledge and action"-analysis of the practice and effect on undergraduates' innovation ability cultivation}

In the past three years, cultivation of undergraduates' innovative abilities has been promoted in the major of communications engineering, and a total of more than 100 undergraduates in communication major and control major have participated in the innovation practice. Undergraduate students majoring in communication engineering have received 1 international silver medal, 3 national special prizes, 3 first prizes, 5 second prizes, and 2 third prizes in international and national university competitions. The statistical data of graduates in the past three years shows that the excellent rate of thesis of undergraduates who participate the innovative ability training reaches $20 \%$, twice as those who do not participate the innovative ability training. The comparative advantages of innovation ability training practices in terms of graduation and excellence, publication of papers, and merit awards are shown in Figure 4. 


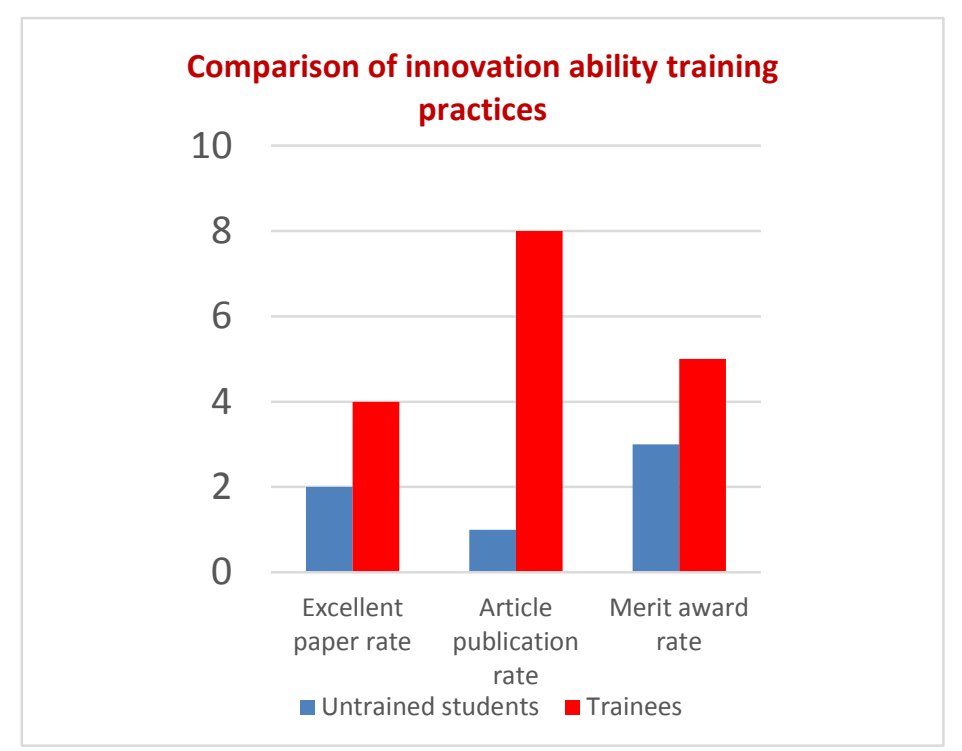

Figure 4 Comparison of practice in innovation ability training

\subsection{Inspiration from innovation ability training}

(1) Reform of the educational philosophy is a prerequisite for the cultivation of innovative ability of undergraduates in higher education institutions

China's famous educator Zhou Yuanqing pointed out that: with regard to university reform, reform of educational system is the forerunner, and reform of the education system is the key, and teaching content and curriculum reform are the core ${ }^{[6]}$. It is enough to show the importance of teaching philosophy. At the same time, the importance of educational system can also be reflected in the history of modern university development. Under the guidance of the concept of liberal education, Newman advocated the teaching concept of "bringing up educated gentlemen", "training elite talents", and "the integration of science education and humanities education", creating an elite education teaching mode, which in turn laid Oxford University as a basic prototype of the modern university; under the guidance of the liberal arts education concept of Greece, Humboldt put forward the educational concepts of "academic freedom, teaching freedom, learning freedom" and "achievement through science", which created a general education teaching mode and created the academic status of Humboldt University and later Harvard University ${ }^{[8]}$.

Today's higher education in the world is experiencing great changes, innovation cultivation has become a trend, and educational concepts are constantly updated, shifting from inheritance-dominance to innovation-dominance. The traditional teaching mode of imparting knowledge has been unable to adapt to the development of the current society. The change of teaching modes in various countries is developing toward inquiry-based learning, practical learning and cooperative learning, in order to cultivate students' spirit of innovation and innovation, from ability-oriented to value-oriented. The ultimate objective of value orientation is to educate students on how to treat themselves, how to treat others, and how to treat society, the country, and the world. From a curriculum-centered shift to a student-centered approach, the training shifts from standardized personality to diverse personality.

2) Advocating the atmosphere of free scholarship is the basis for the cultivation of innovative ability of undergraduates in higher education institutions

It is important to establish an atmosphere for running a university, and a compatible and relaxed education environment is a necessary condition for cultivating outstanding talents. Cambridge University believes that the purpose of student learning is not only to acquire knowledge, but to learn a method to solve problems, while a relaxed and free environment can greatly develop and exploit the potential of students ${ }^{[9]}$. 
In the practice of innovation ability cultivation, advocating of free scholarship is mainly reflected in the freedom of teaching and the freedom of learning. The freedom of teaching refers mainly to giving teachers full freedom in terms of innovative training courses and teaching processes. The freedom of learning mainly refers to the students' freedom to choose any course in the university based on their individual talents and interests in teaching activities, and they are free to change majors. In order to reflect the innovative ability to cultivate the freedom of undergraduate students, we must first uphold the idea of open education, and earnestly implement the credit system of undergraduates, so as to break through major restrictions, so that undergraduate students can have cross-disciplinary and cross-university learning.

(3) Student-centered teaching services and management are the fundamental guarantees for the cultivation of innovative ability of undergraduates in higher education institutions

Students are the main body and business card of the school. All work in the school must be based on the success of the students. Higher education institutions should establish a student-based and teaching-oriented education concept. In terms of teaching, scientific research, and management orientation, teaching should be given top priority and resources should be concentrated on personnel training ${ }^{[10]}$. All departments must shoulder the responsibility for talent cultivation. Each faculty and staff member must take pride in serving students and strive to solve various problems and difficulties in students' life, learning and development, help students move to positions with sound personality, good moral character, developed wisdom, and sense of responsibility and mission of citizens.

\section{Conclusion}

Cultivating first-rate talents is always the fundamental responsibility of the university. University practitioners are first educators or teaching staff. Regarding academics as the where life is, the pursuit of truth as the ultimate objective of education is a mission that university education should uphold. Faced with the demand for innovative talents in the new economic wave, this paper takes the innovation practice of undergraduates majoring in communication engineering as the traction, and puts forward the "integrating knowledge and action" innovation ability training teaching philosophy; establishes the tree-shaped knowledge system and laddered cultivation mode, which is the core idea of innovation and practice; the implementation of a series of new teaching methods such as the "undergraduate tutorial system", and the analysis of teaching practice and effect proves the effectiveness of "integrating knowledge and action", the cultivating mode undergraduates' innovative ability in higher education institutions. It is true that the cultivation of undergraduates' innovative ability needs to be further improved. The front-line educators in the higher education institutions need to actively explore and practice to provide reference for teaching reform in higher education institutions.

\section{References}

[1] Notice of the State Council on Issuing General Plans for Coordinating the Advancement of World-Class Universities and First-Class Disciplines [Z].

[2] Xinhua News Agency, November 2015.Li Keqiang. Speech at The State Science and Technology Awarding Meeting of the People's Republic of China [R]. Xinhua News Agency, January 2017.

[3] The State Council's Opinions on Vigorously Promoting Several Policies and Measures for Mass Innovation by the Public [R]. Xinhua News Agency, June 2015.

[4] Xi Jinping. Speech at the Seventeenth Academician Meeting of the Chinese Academy of Sciences and the Twelfth Academician Conference of the Chinese Academy of Engineering [R]. Xinhua News Agency, June 2014. 
[5] Bie Dunrong, Zhang Zheng. The Characteristics and Enlightenment of Educational Concepts in World-class Universities[J]. Research in Higher Education of Engineering, 2010(6): 56-62.

[6] Lai Shaocong. Innovative Education Teaching Concept to Improve the Quality of Talent Training [J]. Chinese University Teaching, 2016(3):27-31.

[7] Chen Renren. Innovative Undergraduate Tutorial System to Reshape Modern University Education Concept[J]. College Education Science, 2016, 3(157): 64-69.

[8] Bie Dunrong, Jiang Xinbiao. Educational Philosophy of Development Course of Oxford University and Its Enlightenment[J]. Fudan Education Forum, 2011, 9(2): 72-77.

[9] John Henry Newman. The Idea of a University [M]. Foreign Language Teaching and Research Press, December 2001.

[10]Bie Dunrong, Zhang Zheng. Education Concept of World-Class Universities[J]. Research in Higher Education of Engineering, 2010(4):82-92. 